“ (C) 2017 IEEE. Personal use of this material is permitted. Permission from IEEE must be obtained for all other uses, in any current or future media, including

reprinting/republishing this material for advertising or promotional purposes, creating new collective works, for resale or redistribution to servers or lists, or reuse of any copyrighted component of this work in other works." 


\section{Welcome from the General Chair}

The entire organizing committee welcomes you to Sydney. It is our pleasure to be hosting the 2017 IEEE 85 th Vehicular Technology Conference for the first time in Sydney, drawing scientific experts in academia and industry from all over the world.

The aim of this conference is to provide a forum of researches and technologist from academia and industry to present new ideas and contributions in the form of technical papers, panel discussions and tutorials, as well as to contribute to and extend the participant's relationship for fruitful future cooperation activities.

Sydney is a well-known cosmopolitan and multicultural city located in Australia and the capital of the State of New South Wales. The city is famous for its multicultural environment, iconic Sydney Harbour Bridge and Sydney Opera House, excellent restaurants, excellent beaches and nearby attractions such as the world-heritage listed Blue Mountains and the Hunter Valley wine region.

Our organizing committee has worked hard to put together an excellent technical program. We are also very proud of offering in the conference excellent Industry Tracks featuring eminent speakers from industry and government agencies from around the world. We hope you can share with us an exciting social program that introduces you to the best that Sydney has to offer. Last but not least, our special thanks also go to our supporters and patrons: NSW Government for their Unwavering Support; Huawei Technologies Co, Ltd. - Gold Patron; National Instruments Australia Pty Ltd. - Silver Patron; and IEEE Green ICT - Patron for Wireless Internet Access, for their strong and keen support. We wish you warm welcome to Sydney and to the VTC 2017-Spring conference.

Eryk Dutkiewicz, General Chair 